\title{
PENGARUH KOMPENSASI TERHADAP PENINGKATAN KINERJA PEGAWAI PADA BIDANG KEBERSIHAN DAN PERTAMANAN
}

\section{THE EFFECT OF COMPENSATION ON THE IMPROVEMENT OF EMPLOYEES 'PERFORMANCE IN CLEAN AND FIELD FIELDS}

\author{
Ernawati $^{1}$, A Iskandar ${ }^{1 a}$, dan G Pratidina ${ }^{1}$ \\ ${ }^{1}$ Program Studi Ilmu Administrasi Negara, Fakultas Ilmu Sosial dan Ilmu Politik, Universitas Djuanda \\ Bogor, Jl. Tol Ciawi No. 1 Kotak Pos 35 Ciawi Bogor 16720 \\ a Korespondensi: Abubakar Iskandar, Email: abubakar.iskandar@unida.ac.id \\ (Diterima: 11-02-2018; Ditelaah: 12-02-2018; Disetujui: 05-04-2018)
}

\begin{abstract}
Garbage is the remnants of disposal from every production and non-production sources in the form of organic and inorganic. The waste volume from day to day is increasing due to increasing population, improving economic wheels, and changing people's behavior in consumption. Therefore, it is necessary to be compensated so that employees can improve their performance. The study was conducted in the City of Bogor's Hygiene and Landscaping Field, which was held from January to April 2014. The purpose of this study was to find out the realization of compensation, know the improvement of employee performance, and examine the effect of compensation for performance improvement. The method used in this research is qualitative and quantitative descriptive. The population is 184 people and the sample is 65 people. Data collection techniques are observation, questionnaire and documentation, while the data consist of primary data and secondary data. Data analysis in this study is Rank Spearman. The results showed that the correlation coefficient - 216, which means that the relationship between TPP and responsibility according to ability is not significant. - 007 correlation coefficient, which means that the relationship between TPP and work that matches skills is not significant. The results of the study show that the average performance shown in the skills to complete work is 129,000. Because the value of $t$ count $>t$ table, then Ho is accepted, or the average skills owned by employees are the same. The average performance shown in the ability to complete the job is 115,111 . Because the value of $t$ count $>t$ table, then Ho is accepted, or the average ability possessed by the same employee.

Keywords: compensation, employees, performance.
\end{abstract}

\section{ABSTRAK}

Sampah merupakan sisa-sisa pembuangan dari setiap sumber produksi maupun non produksi berupa organik dan anorganik.Volume sampah dari hari ke hari semakin meningkat disebabkan oleh bertambahnya jumlah penduduk, membaiknya roda perekonomian, dan berubahnya perilaku masyarakat dalam berkonsumsi. Oleh karena itu perlu diberikan kompensasi agar pegawai dapat meningkatkatkan kinerjanya. Penelitian dilakukan di Bidang Kebersihan dan Pertamanan Kota Bogor yang dilaksanakan sejak bulan Januari-April 2014.Tujuan penelitian ini adalah mengetahui realisasi pemberian kompensasi, mengetahui peningkatan kinerja pegawai, dan menguji pengaruh pemberian kompensasi terhadap peningkatan kinerja. Metode yang digunakan dalam penelitian ini adalah deskriptif kualitatif dan kuantitatif. Populasi sebanyak 184 orang dan sampel sebesar 65 orang. Teknik pengumpulan data adalah observasi, angket dan dokumentasi, sedangkan data terdiri data primer dan data sekunder. Analisa data dalam penelitian ini adalah Rank Spearman. Hasil 
penelitian menunjukan bahwa koefisien korelasi -,216 yang artinya hubungan antara TPP dengan tanggungjawab sesuai kemampuan tidak signifikan.Koefisien korelasi -,007 yang artinya hubungan antara TPP dengan pekerjaan yang sesuai ketrampilan tidak signifikan.Selanjutnya untuk menguji perbedaan kiner pegawai digunakan uji t. Hasil penelitian menunjjukan bahwa rata-rata kinerja yang ditunjukan pada ketrampilan menyelesaikan pekerjaan adalah 129,000. Oleh karena nilai thitung>ttabel maka Ho diterima, atau rata-rata ketrampilan yang dimiliki pegawai adalah sama.Rata-rata kinerja yang ditunjukan pada kemampuan menyelesaikan pekerjaan adalah 115,111. Oleh karena nilai thitung>ttabel maka Ho diterima, atau rata-rata kemampuan yang dimiliki pegawai sama.

Kata kunci: kompensasi, kinerja, pegawai.

Ernawati, Iskandar, A., \& Pratidina, G. 2018. Pengaruh Kompensasi terhadap Peningkatan Kinerja Pegawai pada Bidang Kebersihan dan Pertamanan. Jurnal Sosial Humaniora 9(1): 61-69.

\section{PENDAHULUAN}

Sampah merupakan sisa-sisa pembuangan dari setiap sumber produksi maupun non produksi berupa organik dan anorganik yang dihasilkan oleh kegiatan bersifat formal maupun informal. Volume sampah dari hari ke hari, tahun ke tahun bukannya semakin berkurang tetapi semakin meningkat. Faktor yang memicu meningkatnya volume sampah antara lain: bertamdahnya jumlah penduduk, membaiknya roda perekonomian, dan berubahnya perilaku masyarakat dalam berkonsumsi.Dinas Kebersihan dan Pertamanan Kota Bogor merupakan salah satu Dinas yang mempunyai tugas pokok melaksanakan kewenangan otonomi pemerintah di bidang lingkungan hidup dan kebersihan. Dalam memelihara, mengelola dan menjaga lingkungan hidup dan kebersihan khususnya yang ditimbulkan dari sampah tidaklah mudah. Upaya yang dilakukan dalam menanggulangi sampah diperlukan sarana parasana, sumber daya manusia, dan anggaran. Sarana prasarana berupa dump truk, arm roll truk, alat berat, pick up, motor gerobak sampah, gerobak sampah, TPS, container, landasan container, lahan TPA dengan kelengkapannya, sedangkan sumber daya manusia (karyawan) merupakan pelaksana yang menjalankan setiap program dan kegiatan yang ditetapkan. Sementara itu, anggaran merupakan alat pembiyaan setiap program dan kegiatan Dinas.

Masalah persampahan di Kota Bogor sekarang ini menjadi sorotan dari khalayak umum karena dampaknya cukup luas diantaranya pencemaran air, kesehatan, sosial dan politik. Untuk itu sesuai RENSTRA (Rencana Strategis) Kota Bogor pada Tahun 2012 menetapkan 70,2\% sampah terangkut dan terbuang ke TPA, dengan asumsi timbulan sampah sebesar $986.746 \mathrm{M}^{3} /$ hari, sampah yang terangkut sebesar 1.732 $\mathrm{M}^{3} /$ hari dan hasil (output) yang dicapai yaitu cakupan wilayah terlayani sebesar $69 \%$. Hal ini merupakan penjabaran dari salah satu Misi Pemerintah Daerah Kota Bogor yaitu " Mewujudkan Kota Bogor yang bersih, indah, tertib dan aman dengan sarana dan prasarana perkotaan yang memadai dan berwawasan lingkungan". Dengan adanya pemberian kompensasi diharapkan pegawai Bidang Kebersihan dan Pertamanan memiliki tingkat kinerja yang tinggi, mengingat semakin kompleksnya tugas-tugas yang dihadapi. Pemberian kompensasi adalah salah satu cara yang tepat untuk meningkatkan kinerja pegawai.

Kinerja menurut Ilyas (1993) merupakan penampilan hasil kerja pegawai baik secara kuantitas maupun kualitas. Kinerja dapat berupa penampilan kerja perorangan 
maupun kelompok. Kinerja organisasi merupakan hasil interaksi yang kompleks dan agregasi kinerja sejumlah individu dalam organisasi. Untuk mengetahui faktor yang mempengaruhi (determinan) kinerja individu, perlu dilakukan pengkajian terhadap teori kinerja. Secara umum faktor fisik dan non fisik sangat mempengaruhi. Berbagai kondisi lingkungan fisik sangat mempengaruhi kondisi karyawan dalam bekerja. Selain itu, kondisi lingkungan fisik juga akan mempengaruhi berfungsinya faktor lingkungan non fisik. Kemudian menurut Thoha (1994:154) kemampuan pegawai didefinisikan sebagai suatu kondisi yang menunjukkan unsur kematangan yang berkaitan pula dengan pengetahuan dan ketrampilan yang dapat diperoleh melalui pendidikan, latihan dan pengetahuan.

Penentuan tujuan setiap unit organisasi merupakan strategi untuk meningkatkan kinerja. Tujuan ini akan memberikan arah dan mempengaruhi bagaimana seharusnya perilaku kerja yang diharapkan organisasi dari setiap personel. Tetapi ternyata tujuan saja tidak cukup, sebab itu diperlukan ukuran apakah seseorang personel telah mencapai kinerja yang diharapkan. Untuk itu penilaian kuantitatif dan kualitatif standar kinerja untuk setiap tugas dan jabatan personel memegang peranan yang penting. Akhir dari proses kinerja adalah penilaian kinerja itu sendiri yang dikaitkan dengan proses pencapaian tujuan. Kompensai yang diberikan bisa berupa pemberian tunjangan perbaikan penghasilan, tunjangan hari raya, asuransi kesehatan, dan uang pensiun.

Berdasarkan pengamatan, pemberian kompensasi untuk pegawai Bidang Kebersihan dan Pertamanan dinilai masih kurang, sehingga berpengaruh negatif terhadap semangat dan prestasi kerja. Dinas Kebersihan dan Pertamanan Kota Bogor menetapkan pemberian kompensasi sesuai dengan peraturan yang berlaku yang telah diundangkan oleh pemerintah, dan pemberian kompensasi tersebut ditetapkan berdasarkan waktu pembayarannya, masa kerja, dan tingkat pendidikan. Tugas yang diemban.

Robbins (1996:218) menyatakan bahwa tingkat kinerja pegawai sangat tergantung kedua faktor yaitu kemampuan pegawai itu sendiri, seperti tingkat pendidikan, pengetahuan, pengalaman, dimana dengan tingkat kemampuan yang semakin tinggi akan mempunyai kinerja semakin tinggi pula. Faktor lain adalah motivasi kerja pegawai yaitu dorongan dari dalam pegawai untuk melakukan suatu pekerjaan. Dengan motivasi kerja yang tinggi akan mempunyai kinerja tinggi dan sebaliknya. Sehingga dapat disimpulkan bahwa kedua faktor yaitu motivasi dan kemampuan mempunyai hubungan yang positif. Mangkunegara (2006) mendefinisikan kinerja (prestasi kerja) sebagai berikut: "Kinerja adalah hasil kerja secara kualitas dan kuantitas yang dicapai seorang pegawai dalam melaksanakan tugasnya sesuai dengan tanggung jawab yang diberikan kepadanya.

Bidang Kebersihan dan Pertamanan sangatlah berat dalam usaha menyisir, mengumpulkan dan mengangkut sampah ke TPS-TPS yang tersedia. Namun masih ada sejumlah masalah dalam hal kinerja pegawai, khususnya kinerja pegawai Bidang Kebersihan. Adapun kendala atau masalah saat ini yaitu (a) fluktuatif atau naik turunnya semangat, motivasi dan disiplin pegawai Bidang Kebersihan dan Pertamanan, (2) ketidakstabilan produktivitas pegawai Bidang Kebersihan dan Pertamanan dalam melaksanakan tugasnnya, dan (3) penghargaan dan pengakuan produktivitas kerja pegawai Bidang Kebesihan dan Pertamanan belum optimal.

\section{MATERI DAN METODE}

\section{Desain dan Lokasi}

Desain penelitian ini adalah deskriptif kualitatif dan kuantitatif, sedangkan lokasi penelitian dilaksanakan di Kantor Dinas Kebersihan dan Pertamanan Kota Bogor pada Bidang Kebersihan. 


\section{Populasi dan Sampel}

Populasi dalam penelitian ini adalah pegawai pada Bidang Kebersihan dan Pertamanan.Kota Bogorebanyak 184 orang , sedangkan sampel sebanyak 65 orang yang diambil dari : Kerpala Bidang 1 orang, Kepala Seksi 1 orang, staf 1 orang dan petugas lapangan 62 orang. Dengan demikian teknik sampling dalam penelitian adalah Disproportionale Stratified Random Sampling yaitu teknik pengambilan sampel yang memberikan peluang yang sama bagi setiap unsur populasi untuk terpilih menjadi anggota sampel (Sugiyono, 2009:82).

\section{Teknik Pengumpulan Data}

1. Observasi yaitu pengamatan yang telah dirancang secara sistematis, tentang apa yang akan diamati, kapan dan dimana tempatnya.

2. Wawancara dengan berpedoman pada kuesioner terstruktur yang dilakukan dengan cara memberi seperangkat pertanyaan baik pertanyaan tertutup maupun pertanyaan terbuka secara tertulis kepada responden untuk dijawabnya. Menyangkut pertanyaan tentang tingkat kepuasan kompensasi yang diberikan dan tanggungjawab yang dibebankan kepada pegawai yang bersangkutan, menggunakan skala likert dengan interval 1-5. Menyangkut tingkat kepuasan, pertanyaan dengan jawaban sangat puas dengan nilai 5 dan sampai dengan sangat tidak puas dengan nilai 1 (satu). Demikian pula tanggugngjawab sesuai kemampuan, pertanyaan juga dengan jawaban sangat sesuai dengan nilai 5 dan sampai dengan sangat tidak sesuai dengan nilai 1 . Kriteria penilaian untuk angket pada kedua unsur pertanyaan (tingkat kepuasan dan tanggungjawab sesuai kemampuan adalah sebagai berikut.

\section{Skor terbesar - Skor terkecil} Jumlah Skor

Selanjutnya dianalisis dengan teknik analisis Weight Mein Score (WMS), dengan rumus sebagai berikut.

$$
M=\frac{\sum f(x)}{n}
$$

3. Dokumentasi adalah catatan yang sudah berlalu, bisa berbentuk tulisan, (catatan harian, sejarah kehidupan, cerita, biografi, peraturan, kebijakan), dokumen berbentuk gambar (foto, gambar hidup, sketsa).

\section{Jenis Data}

1. Data Primer yaitu data yang diperoleh dari responden .

2. Data sekunder yaitu data yang diperoleh dari sumber lain yang relevan misalnya dari Dinas Pekerjaan Umum, Dinas Pariwisata, dan lain-lain.

\section{Analisis Data}

Analisis data dalam penelitian in adalah analisa statistik inferensial (statistik probabilitas) adalah teknik statistik yang digunakan untuk menganalisis data sampel dan hasilnya diberlakukan untuk populasi (Sugiyono, 2009:148). Dalam penelitian ini peluang kesalahan 5\%, dan taraf kepercayaan 95\%.. Untuk mengetahui berapa besar pengaruh kompensasi terhadap kinerja pegawai, maka digunakan analisa hubungan, sehingga untuk menguji hipotesis pengaruh antara variabel independen dengan variabel dependen serta untuk menghitung koefisien korelasi menggunakan bantuan komputer program SPSS versi 16.0.Analisa data mengunakan korelasi Rank Spearman.

Menurut Sugiyono (2002:282) korelasi spearman rank digunakan mencari atau untuk menguji signifikansi hipotesis asosiatif bila masing-masing variabel yang dihubungkan berbentuk ordinal, dan sumber data antar variabel tidak harus sama. Selanjutnya untuk mengetahui keeretan hubungan antara variabel $\mathrm{X}$ dengan Y, dapat menggunakan rumus sebagai berikut.

$$
r_{s}=1-\frac{6 \sum d i^{2}}{n\left(n^{2}-1\right)}
$$


Keterangan: $r_{s}=$ koefisien korelasi Spearman; $d_{i}$ $=$ perbedaan rangking antara pasangan data; $\Sigma=$ notasi jumlah; $\mathrm{n}=$ banyaknya pasangan data.

Sementara itu, untuk mengetahui perbedaan kinerja digunakan uji $t$ dengan menggunakan rumus sebagai berikut.

$$
t=r \sqrt{\frac{n-2}{1-r^{2}}}
$$

Keterangan: $t=\mathrm{t}$ hitung; $r=$ nilai korelasi Rank Spearman; $n=$ jumlah sample.

\section{HASIL DAN PEMBAHASAN \\ Persepsi Pegawai terhadap Kompensasi yang Diberikan}

Hasil penelitian menunjukan bahwa $100,0 \%$ mengatakan gaji yang dibayar tepat waktu. Selanjutnya 73,8 \% mengatakan bahwa gaji yang diterima sudah sesuai kebutuhan hidup, sedangkan 26,2 \% mengatakan tidak sesuai dengan kebutuhan hidup.

Tabel 1 Persepsi responden terhadap gaji dan pensiun yang diterima

\begin{tabular}{lllll}
\hline No & Variabel & $\begin{array}{c}\text { Jawaban } \\
\text { Responden }\end{array}$ & $\mathrm{n}$ & \multicolumn{1}{c}{$\%$} \\
\hline 1 & Ketepatan & Ya & 65 & 100,0 \\
& Pembayaran & Tidak & 0 & 0,0 \\
& Gaji & Total & 65 & 100,0 \\
2 & Kecukupan & Ya & 48 & 73,8 \\
& Gaji Pegawai & Tidak & 17 & 26,2 \\
& & Total & 65 & 100,0 \\
3 & Kecukupan & Ya & 53 & 81,5 \\
& Gaji Pensiun & Tidak & 12 & 18,5 \\
& & Total & 65 & 100,0 \\
4 & Asuransi & Ya & 54 & 83,0 \\
\hline
\end{tabular}

\begin{tabular}{llll} 
membantu & Tidak & 11 & 17,0 \\
pengobatan & Total & 65 & 100,0 \\
\hline
\end{tabular}

Dilain pihak 81,5 \% mengatakan bahwa pensiun yang diterima tidak mencukup kebutuhan hidup sehari-hari. Sementara itu, 83,0 \% mengatakan asuransi kesehatan dapat membantu jika memerlukan pengobatan, sedangkan 17,0 \% mengatakan tidak membantu jika memerlukan pengobatan. Secara lengkap dapat dilihat pada Tabel 1.

Sesuai identifikasi gaji yoang diterima pegawai, maka dapat diklasifikasikan menjadi delapan klasifikasi, seperti dapat dilihat pada Tabel 2 .

Tabel 2 Klasifikasi gaji pegawai

\begin{tabular}{lcrr}
\hline No & Klasifikasi Gaji & \multicolumn{1}{c}{$\mathrm{n}$} & \multicolumn{1}{c}{$\%$} \\
\hline 1 & $1.500 .000-1,999,999$ & 13 & 20,0 \\
2 & $2.000 .000-2.499,999$ & 18 & 27,7 \\
3 & $2.500 .000-2.999 .999$ & 25 & 38,4 \\
4 & $3.000 .000-3.499,999$ & 4 & 6,2 \\
5 & $3.500 .000-3,999.999$ & 5 & 7,7 \\
6 & $4.000 .000-4.499 .999$ & - & - \\
7 & $4.500 .000-4.999 .999$ & - & - \\
8 & $>5.000 .000$ & 1 & 1,5 \\
Total & 65 & 100,0 \\
\hline
\end{tabular}

Selanjutnya mengenai tingkat kepuasan kompensasi yang diberikan ternyata bahwa pernyataan tentang tingkat kepuasan kompensasi yang diberikan diperoleh angka penafsiran 3,8 maka berdasarkan kriteria penilaian masuk dalam kategori "puas". Dimana dalam frekuensi jawaban sangat puas (SP) sebanyak 4,6\%), yang puas (P) sebanyak $72,3 \%$, dan yang mengatakan cukup puas sebanyak 23,1 \%.. Secara rinci dapat dilihat pada Tabel 3 .

Tabel 3 Kepuasan responden terhadap tunjangan perbaikan penghasilan

\begin{tabular}{|c|c|c|c|c|c|}
\hline No. & Alternatif Jawaban & $\mathrm{f}$ & $(\mathrm{x})$ & $f(x)$ & $M=\frac{\sum f(x)}{n}$ \\
\hline 1. & Sangat Puas & 3 & 5 & 15 & $248 / 65$ \\
\hline 2. & Puas & 47 & 4 & 188 & \\
\hline 3. & Cukup Puas & 15 & 3 & 45 & \\
\hline 4. & Tidak Puas & 0 & 2 & 0 & \\
\hline 5. & Sangat Tidak Puas & 0 & 1 & 0 & \\
\hline
\end{tabular}


Jumlah

Berdasarkan data tersebut di atas maka menurut Iskandar (2012) bahwa kepuasan adalah suatu keadaan pada saat keluarga merasa lega, puas dan senang karena memenuhi keinginan atau hasrat yang dicita-citakan. Keinginan dan hasrat tersebut menyangkut finansial (uang) dan materi;

\section{Kinerja Pegawai Negeri Sipil}

Hasil penelitian menunjukan bahwa sebanyak 98,5 \% mengatakan bahwa pekerjaan yang dilakukan sesuai ketrampilan, sedangkan 1,5\% mengatakan bahwa pekerjaan yang dilakukan tidak sesuai dengan ketrampilan. Selanjutnya

Tabel 4 Kinerja pegawai negeri sipil
$130 / 2=65$

248
3,8

hasil penelitian menunjukan bahwa sebanyak 83,0 \% mengatakan bahwa pemberian tanggungjawab sesuai kepampuan, sedangkan sebanyak 17,0\% mengatakan bahwa pemberian tanggungjawab tidak sesuai kepampuan Secara lengkap dilihat pada Tabel 4. Selanjutnya, mengenai tanggungjawab yang diberikan saat ini sesuai dengan kemampuan ternyata bahwa pernyataan tentang tanggungjawab yang diberikan sesuai kemampuan diperoleh angka penafsiran 4,0 maka berdasarkan kriteria penilaian masuk dalam kategori sangat sesuai.

\begin{tabular}{|c|c|c|c|c|}
\hline No & Variabel & $\begin{array}{l}\text { Jawaban } \\
\text { Responden }\end{array}$ & $\mathrm{n}$ & $\%$ \\
\hline \multirow[t]{3}{*}{1} & \multirow[t]{3}{*}{ Pembagian Kerja yang Jelas } & Ya & 65 & 100,0 \\
\hline & & Tidak & 0 & 0,0 \\
\hline & & Total & 65 & 100,0 \\
\hline \multirow[t]{3}{*}{2} & \multirow[t]{3}{*}{ Pekerjaan Sesuai Ketrampilan } & Ya & 64 & 98,5 \\
\hline & & Tidak & 1 & 1,5 \\
\hline & & Total & 65 & 100,0 \\
\hline \multirow[t]{3}{*}{3} & \multirow[t]{3}{*}{ Lembur Pekerjaan } & Ya & 65 & 100,0 \\
\hline & & Tidak & 0 & 0 \\
\hline & & Total & 65 & 100,0 \\
\hline \multirow[t]{3}{*}{4} & \multirow{3}{*}{$\begin{array}{l}\text { Pemberian } \\
\text { Kemampuan }\end{array}$} & Ya & 54 & 83,0 \\
\hline & & Tidak & 11 & 17,0 \\
\hline & & Total & 65 & 100,0 \\
\hline \multirow[t]{3}{*}{5} & \multirow[t]{3}{*}{ Pekerjaan yang Dilaksanakan Tepat Waktu } & Ya & 65 & 100,0 \\
\hline & & Tidak & 0 & 0,0 \\
\hline & & Total & 65 & 100,0 \\
\hline \multirow[t]{3}{*}{6} & \multirow{3}{*}{$\begin{array}{l}\text { Menyampaikan usulan atau pendapat kepada } \\
\text { atasan dalam rangka evaluasi pekerjaan }\end{array}$} & Ya & 52 & 80.0 \\
\hline & & Tidak & 13 & 20,0 \\
\hline & & Total & 65 & 100,0 \\
\hline \multirow[t]{3}{*}{7} & \multirow{3}{*}{$\begin{array}{l}\text { Mendapat teguran apabila terlambat } \\
\text { hadir di tempat kerja }\end{array}$} & Ya & 65 & 100,0 \\
\hline & & Tidak & 0 & 0,0 \\
\hline & & Total & 65 & 100,0 \\
\hline \multirow[t]{3}{*}{8} & \multirow{3}{*}{$\begin{array}{l}\text { Menerima waktu libur sesuai dengan } \\
\text { peraturan yang ditetapkan }\end{array}$} & Ya & 65 & 100,0 \\
\hline & & Tidak & 0 & 0,0 \\
\hline & & Total & 65 & 100,0 \\
\hline
\end{tabular}

Dimana dalam frekuensi jawaban sangat sesuai (SS) sebanyak 3,1\%, yang sesuai (S) sebanyak 95,4\% yang mengatakan cukup sesuai. Secara rinci dilihat pada Tabel 5 . 
Tabel 5 Tanggungjawab saat ini sesuai kemampuan

\begin{tabular}{llrrrr}
\hline \multirow{2}{*}{ No } & \multicolumn{1}{c}{ Alternatif Jawaban } & $\mathrm{f}$ & $\mathrm{T}$ & $\mathrm{f}(\mathrm{x})$ & $M=\frac{\sum f(x)}{n}$ \\
& & 2 & 5 & 10 & $261 / 65$ \\
1 & Sangat Sesuai & 62 & 4 & 248 & \\
2 & Sesuai & 1 & 3 & 3 & \\
3 & Cukup Sesuai & 0 & 2 & 0 & \\
4 & Tidak Sesuai & 0 & 1 & 0 & \\
5 & Sangat Tidak Sesuai & $130 / 2=65$ & & 261 & 4,0 \\
\hline
\end{tabular}

Hubungan antara Kompensasi dan Kinerja Pegawai kemampuan dan ketrampilan dapat dijelaskan seperti pada Tabel 6 .

Hubungan antara tunjangan perbaikan penghasilan dengan pembagian kerja,

Tabel 6 Hubungan antara tunjangan perbaikan penghasilan dengan pembagian kerja, kemampuan dan ketrampilan

\begin{tabular}{|c|c|c|c|c|c|c|}
\hline \multicolumn{7}{|c|}{ Correlations } \\
\hline & & & TPP & Keterampilan & $\begin{array}{c}\text { Pembagian } \\
\text { Kerja }\end{array}$ & Kemampuan \\
\hline \multirow[t]{13}{*}{$\begin{array}{l}\text { Rank } \\
\text { Spearman }\end{array}$} & TPP & $\begin{array}{l}\text { Koefisien } \\
\text { Korelasi }\end{array}$ & 1,000 &,- 147 & . &,- 216 \\
\hline & & Sig (2 tailed & & ,244 & . & 084 \\
\hline & & $\mathrm{N}$ & 65 & 65 & 65 & 65 \\
\hline & Ketrampilan & $\begin{array}{l}\text { Koefisien } \\
\text { Korelasi }\end{array}$ & -147 & 1,000 & . &,- 007 \\
\hline & & Sig (2 tailed & , 244 & . & . & ,955 \\
\hline & & $\mathrm{N}$ & 65 & 65 & 65 & 65 \\
\hline & Pembagian & Koefisien & & & & \\
\hline & Kerja & Korelasi & · & & $\cdot$ & \\
\hline & & Sig (2 tailed & . & & . & \\
\hline & & $\mathrm{N}$ & 65 & 65 & 65 & 65 \\
\hline & Kemampuan & $\begin{array}{l}\text { Koefisien } \\
\text { Korelasi }\end{array}$ &,- 216 &,- 007 & . & 1,000 \\
\hline & & Sig (2 tailed & , 084 & ,955 & . & \\
\hline & & $\mathrm{N}$ & 65 & 65 & 65 & 65 \\
\hline
\end{tabular}

Angka koefisien korelasi -,216 artinya hubungan antara TPP dengan tanggungjawab yang diberikan sesuai kemampuan pegawai yang bersangkutan tidak signifikan. Koefisien korelasi bertanda negatif (-) artinya hubungannya tidak searah, jadi walaupun pemberian TPP diberikan kepada seorang pegawai sesuai tanggungjawab yang diberikan, pegawai tersebut tetap menjalankan tanggungjawabnya sesuai kemampuannya. Angka koefisien korelasi -,007 artinya hubungan antara TPP dengan pekerjaan yang diberikan sesuai ketrampilan pegawai yang bersangkutan tidak signifikan. Koefisien korelasi bertanda negatif (-) artinya hubungannya tidak searah, jadi walaupun pemberian TPP kepada seorang pegawai sesuai ketrampilannya, namun pegawai tersebut tetap menjalankan pekerjaaanya sesuai ketrampilan yang dimulikinya. Sementara itu, untuk pembagian kerja kepada seluruh karyawan, merupakan hal yang sudah ditetapkan/diatur di instansi mana saja termasuk bidang kebersihan dan 
pertamanan Kota Bogor, sehingga dalam analisisi tersebut tidak terdapat angka koefisien korelasi, karena pembagian kerja itu sudah ada ketika seorang pegawai telah menjadi bagian dari Bidang atau Seksi tersebut.dimana ia bekerja dan otomatis kompensasi akan mengikutinya.
Selanjutnya, untuk menguji apakah ratarata sampel yang ada berbeda nyata atau tidak nyata, dengan suatu nilai tertentu yang digunakan sebagai pembanding misalnya apakah semua karyawan yang memperoleh kompensasi memiliki kinerja yang tinggi atau tidak digunakan uji t satu sampel (One Sample t Test).

Tabel 7 One-Sample Statistics

\begin{tabular}{lrrrr}
\hline \multicolumn{1}{c}{ Kinerja } & N & Mean & Std. Deviation & Standar Error Mean \\
\hline Ketrampilan & 65 & 1,98 &, 124 &, 015 \\
Tanggungjawab & 65 & 2,00 &, $000(\mathrm{a})$ &, 000 \\
Kemampuan & 65 & 3,98 &, 279 &, 035 \\
\hline
\end{tabular}

a t cannot be computed because the standard deviation is 0 .

Pada tabel 7 One-Sample Statistics memberikan gambaran atau deskripsi data yang ada. Jumlah data adalah 65 , rata-rata kinerja yang ditunjukan pada ketrampilan menyelesaikan pekerjaan 1,98 dengan standar deviasi ,124 dan standar error 0,015, sedangkan rata-rata kinerja yang ditunjukan pada tanggungjawab yang

Tabel 8 One-Sample Test dibebankan untuk menyelesaikan pekerjaan 2,00 dengan standar deviasi 0,000(a) dan standar error 0,000 . Sementara itu, ratarata kinerja yang ditunjukan pada kemampuan dalam menyelesaikan pekerjaan 3,98 dengan standar deviasi 0,279 dan standar error 0,035 .

\begin{tabular}{|c|c|c|c|c|c|c|}
\hline \multirow{3}{*}{ Kinerja } & \multicolumn{6}{|c|}{ Test Value $=0$} \\
\hline & \multirow[t]{2}{*}{$\mathrm{t}$} & \multirow[t]{2}{*}{$\mathrm{df}$} & \multirow{2}{*}{$\begin{array}{l}\text { Sig. (2- } \\
\text { tailed) }\end{array}$} & \multirow{2}{*}{$\begin{array}{c}\text { Mean } \\
\text { Difference }\end{array}$} & \multicolumn{2}{|c|}{$\begin{array}{c}\text { 95\% Confidence Interval of } \\
\text { the Difference }\end{array}$} \\
\hline & & & & & Lower & Upper \\
\hline Ketrampilan & 129,000 & 64 & , 000 & 1,985 & 1,95 & 2,02 \\
\hline Kemampuan & 115,111 & 64 & ,000 & 3,985 & 3,92 & 4,05 \\
\hline
\end{tabular}

Pada tabel 8 One-Sample Test

$\mathrm{H}_{\mathrm{o}}=$ rata-rata ketrampilan dan kemampuan pegawai adalah tinggi

$\mathrm{H}_{\mathrm{a}}=$ rata-rata ketrampilan dan kemampuan pegawai adalah tidak tinggi

Pengambilan keputusan:

Dengan membandingkan $t_{\text {hitung }}$ dengan $t_{\text {tabel }}$

Jika $t_{\text {tabel }}<t_{\text {hitung }}<t_{\text {tabel }} \mathrm{H}_{\mathrm{o}}$ diterima

Jika thitung $<t_{\text {hitung }}<t_{\text {tabel }}$ atau $t_{\text {hitung }}>t_{\text {tabel }} H_{o}$ ditolak

Dengan membandingkan nilai probabilitas dengan alpha:

Jika probabilitasnya $>0,05$ maka $\mathrm{H}_{\mathrm{o}}$ diterima Jika probabilitasnya $<0,05$ maka $\mathrm{H}_{\mathrm{o}}$ ditolak
Rata-rata kinerja yang ditunjukan pada ketrampilan menyelesaikan pekerjaan adalah 129,000

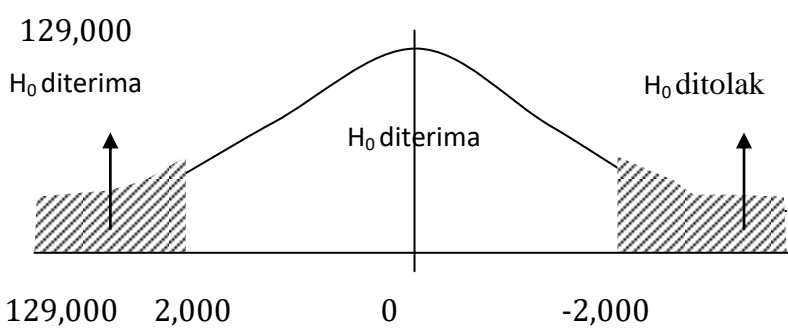

Gambar 3 Kurva penerimaan dan penolakan hipotesis ketrampilan

$t_{\text {tabel }}$ pada taraf kepercayaan $95 \%$ (5 \%) dan derajat bebas (df) $n-1$ atau 65-1=64

Uji t akan dilakukan dengan uji dua sisi (2-tailed) karena akan diuji apakah rata-rata ketrampilan yang dimiliki pegawai sama 
tinggi, jadi bisa lebih tinggi atau lebih rendah. Oleh karena dilakukan uji 2 sisi maka untuk membaca $t_{\text {tabel }}$ pada kolom alpha digunakan $\frac{1 / 2}{\text { a }}$ atau $\mathrm{t} 1 / 2 \mathrm{2} 0,05=\mathrm{t}$ 0,025

$t_{\text {tabel }}(0,025 ; 64) \mid-2,000$

Oleh karena nilai $t_{\text {hitung }}>t_{\text {tabel }}$ maka kesimpulannya $\mathrm{H}_{0}$ diterima, atau rata-rata ketrampilan yang dimiliki pegawai adalah sama.

Rata-rata kinerja yang ditunjukan pada kemampuan menyelesaikan pekerjaan adalah 115,111

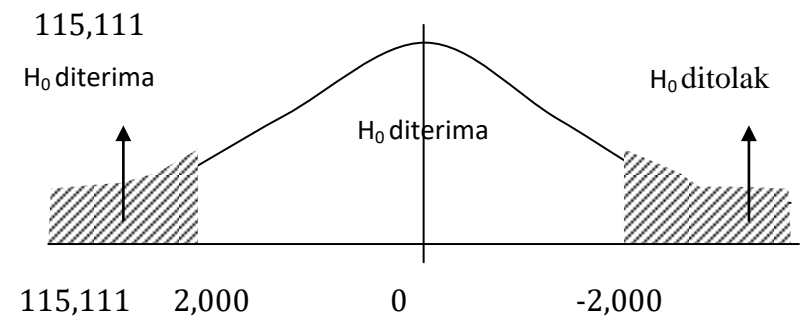

Gambar 4 Kurva penerimaan dan penolakan hipotesis kemampuan

$t_{\text {tabel }}$ pada taraf kepercayaan $95 \%$ (5\%) dan derajat bebas (df) n-1 atau 65-1=64

Uji t akan dilakukan dengan uji dua sisi (2-tailed) karena akan diuji apakah rata-rata ketrampilan yang dimiliki pegawai sama tinggi, jadi bisa lebih tinggi atau lebih rendah. Oleh karena dilakukan uji 2 sisi maka untuk membaca tabel pada kolom alpha digunakan $\frac{1 / 2}{\text { a }}$ atau $\mathrm{t} 1 / 20,05=\mathrm{t}$ 0,025

$t_{\text {tabel }}(0,025 ; 64) \mid-2,000$

Oleh karena nilai $t_{\text {hitung }}>t_{\text {tabel }}$ maka kesimpulannya $\mathrm{H}_{0}$ diterima, atau rata-rata kemampuan yang dimiliki pegawai sama.

\section{KESIMPULAN DAN IMPLIKASI}

1. Realisasi pemberian kompensasi Bidang Kebersihan pada Dinas Kebersihan dan Pertamanan Kota Bogor adalah gaji,uang pensiun, tunjangan perbaikan penghasilan (TPP dan asuransi kesehatan).

2. Kinerja pegawai Bidang Kebersihan dan Pertamanan pada Dinas Kebersihan dan Pertamanan Kota Bogor secara rutin menyisir, mengumpulkan dan mengangkut sampah ke TPS-TPS di tracking (jalur) jalan ke Tempat Pembuangan Akhir (TPA).

3. Tidak ada pengaruh pemberian kompensasi terhadap ketrampilan dan kemampuan yang dimiliki pegawai dalam menyisir, mengumpulkan dan mengangkut sampah ke TPS-TPS di tracking (jalur) jalan ke Tempat Pembuangan Akhir (TPA).

\section{DAFTAR PUSTAKA}

Rentra Kota Bogor, 2012 Dinas Kebersihan dan Pertamanan Kota Bogor

Sugiyono, (2002), Metode Penelitian Bisnis, Alfabeta, Bandung.

Sugiyono, (2009), Metode Penelitian Kuantitatif Kualitatif. Alfabeta, Bandung.

Mifta, T. 1994. Dimensi=Dimensi Prima Ilmu Administrasi Negara.PT. RajaGrafindo Perkasa. Jakarta

Iskandar, A. 2012. Benchmarking Kemiskinan, IPB Press. Bogor

Ilyas, Y., 2002, Kinerja (Teori dan Penilaian), Jakarta: Pusat Kajian Ekonomi. Kesehatan FKM

Mangkunegara, Anwar Prabu, 2006. Manajemen Sumber Daya Manusia Perusahaan, Cetakan Ketujuh, Penerbit PT. Remaja Rosdakarya, Bandung.

Stephen P Robins, (1996), Perilaku Organisasi, Konsep, Kontroversi dan Aplikasi. Alih Bahasa : Handyana Pujaatmaka, Edisi Keenam, PT Bhuana Ilmu Populer, Jakarta. 